\title{
Synthesis of poly(diphenylacetylene)s bearing various polar groups and their gas permeability
}

\author{
Toshikazu Sakaguchi and Tamotsu Hashimoto
}

Diphenylacetylenes having a diisopropylphenoxysilyl, 2-bromoethoxy, trimethylsilyl and $t$-butyl groups ( $p$-PhOS $i(i-\operatorname{Pr})_{2} \mathrm{C}_{6} \mathrm{H}_{4} \mathrm{C} \equiv$ $\mathrm{CC}_{6} \mathrm{H}_{4}-p-\mathrm{SiMe}_{3}$ (1a), $p-\left(\mathrm{BrCH}_{2} \mathrm{CH}_{2} \mathrm{O}\right) \mathrm{C}_{6} \mathrm{H}_{4} \mathrm{C} \equiv \mathrm{CC}_{6} \mathrm{H}_{4}-p-\mathrm{SiMe}_{3}(1 \mathrm{~b}), \mathrm{PhC} \equiv \mathrm{CC}_{6} \mathrm{H}_{4}-p-\mathrm{SiMe}_{3}$ (1c), $\left.\mathrm{PhC} \equiv \mathrm{CC}_{6} \mathrm{H}_{4}-p-t-\mathrm{Bu}(1 \mathrm{~d})\right)$ were polymerized to provide the corresponding poly(diphenylacetylene)s (2a-d). Treatment of the membrane of 2a with $n$ - $\mathrm{Bu}_{4} \mathrm{~N}^{+} \mathrm{F}^{-}$gave silanol-functionalized poly(diphenylacetylene) (3a). Fourier transform-infrared spectroscopy spectrum of 3a revealed that some silanol groups were consumed and the polymer was crosslinked via siloxane bond. The membrane of $3 a$ exhibited very high gas permeability irrespective of the presence of polar silanol groups. Substitution of 1-methylimidazole to the membrane of $2 b$ afforded an imidazolium salt-containing poly(diphenylacetylene) $\left(3 \mathrm{~b}\left(\mathrm{Br}^{-}\right)\right)$. Counteranions of $3 b\left(\mathrm{Br}^{-}\right)$ could be exchanged by the treatment of the membrane with $\mathrm{CF}_{3} \mathrm{COOK}$ and $\left(\mathrm{CF}_{3} \mathrm{SO}_{2}\right)_{2} \mathrm{NLi}$, and membranes of $3 \mathrm{~b}\left(\mathrm{TFAc}^{-}\right)$and $3 \mathrm{~b}\left(\mathrm{Tf}_{2} \mathrm{~N}^{-}\right)$were obtained. Introduction of 1-methylimidazole remarkably increased the selectivity $\left(P_{\mathrm{CO} 2} / P_{\mathrm{N} 2}=31-44\right)$. The $P_{\mathrm{CO} 2}$ values of $3 \mathrm{~b}\left(\mathrm{Br}^{-}\right), 3 \mathrm{~b}\left(\mathrm{TFAc}^{-}\right)$and $3 \mathrm{~b}\left(\mathrm{Tf}_{2} \mathrm{~N}^{-}\right)$were 11,23 and 53 barrers, respectively, indicating that the $\mathrm{CO}_{2}$ permeability increased as the counteranion became bulkier. Polymers $2 \mathrm{c}$ and $2 \mathrm{~d}$ were sulfonated using acetyl sulfate to give sulfonated poly(diphenylacetylene)s ( $3 \mathrm{c}$ and $3 \mathrm{~d}$ ). Polymer $3 \mathrm{c}$ exhibited high $\mathrm{CO}_{2}$ permselectivity, and the $P_{\mathrm{CO} 2} / P_{\mathrm{N} 2}$ was as large as 54. Polymer $3 \mathrm{~d}$ with $t$-butyl groups showed relatively large $P_{\mathrm{cO} 2}$ of 180 barrers and $P_{\mathrm{co} 2} / P_{\mathrm{N} 2}$ of 30 .

Polymer Journal (2014) 46, 391-398; doi:10.1038/pj.2014.16; published online 9 April 2014

Keywords: carbon dioxide; gas permeability; membrane; permselectivity; polar group; poly(diphenylacetylene)

\section{INTRODUCTION}

Polymeric gas separation membranes gather much attention as they have the possibility of providing solutions to the energy and environmental problems. ${ }^{1-5}$ In general, polyacetylenes with bulky spherical substituents exhibit high gas permeability, for example, the $P_{\mathrm{O} 2}$ values of poly(1-trimethylsilyl-1-propyne) and poly(1-( $p$ trimethylsilyl)phenyl-2-phenylacetylene) reach up to 9000 and 1500 barrers, respectively. ${ }^{6-9}$ This is attributable to the combination of the stiff main chain composed of alternating double bonds and the steric repulsion of the bulky substituents leading to the sparse structure of the membranes on the molecular level. ${ }^{10}$ Further, poly(1trimethylsilyl-1-propyne) and poly(1-( $p$-trimethylsilyl)phenyl-2phenylacetylene) exhibit good solubility in organic solvents, filmforming ability and high thermal stability (the onset temperature of weight loss in air is $\left.450{ }^{\circ} \mathrm{C}\right) .{ }^{8}$ Thus, poly (1-trimethylsilyl-1-propyne) and poly(1-( $p$-trimethylsilyl)phenyl-2-phenylacetylene) are promising materials for gas separation membranes, and a large number of poly(diphenylacetylene)s have been synthesized so far. ${ }^{10-13}$ On the other hand, the incorporation of polar groups into a polymer is of interest as membranes that separate carbon dioxide from light gases (e.g., $\mathrm{N}_{2}, \mathrm{H}_{2}$ and $\mathrm{CH}_{4}$ ), because the polymers containing polar groups tend to show high $\mathrm{CO}_{2}$ permselectivity. This is because polar groups in the polymer membranes interact with $\mathrm{CO}_{2}$ molecules, and the membranes preferentially dissolve $\mathrm{CO}_{2}$ molecules. ${ }^{14}$ This fact suggests that poly(diphenylacetylene)s having polar groups possibly become high-performance membranes, which achieve both high permeability and high permselectivity. Therefore, our aim is to synthesize novel poly(diphenylacetylene)s bearing polar groups. However, poly(diphenylacetylene)s having polar groups cannot be obtained directly by the polymerization of the corresponding acetylene monomers because the Ta catalyst is deactivated by polar groups in the monomer. Based on this fact, we have synthesized poly(diphenylacetylene)s bearing various polar groups by the polymer reaction.

The incorporation of polar functional groups such as hydroxy groups into the poly(diphenylacetylene)s leads to significant decrease of gas permeability on the polymer membranes. ${ }^{15-17}$ In contrast, poly(substituted acetylene)s bearing silyl groups $\left(-\mathrm{SiR}_{3}\right)$ generally exhibit high gas permeability because high local mobility of silyl groups promotes gas diffusion in the polymer matrix. ${ }^{18,19}$ Therefore, poly(diphenylacetylene) having silanol groups $\left(-\mathrm{Si}(\mathrm{OH}) \mathrm{R}_{2}\right)$ as a functional group is expected to become an interesting polar material with high gas permeability. In addition, polymers carrying silanol groups can be used as a reactive polymer for the polymer reaction. 
Silanol groups are highly reactive, and they can undergo hydrolysis and condensation reaction with other reagents. For instance, they are promising polymers as organic components to prepare organicinorganic hybrid materials through sol-gel method using tetraethoxysilane. $^{20-23}$

Room temperature ionic liquids have attracted great interest because of their unique properties, such as nonvolatility, high ionic conductivity, good thermal stability and tunable solvation properties. ${ }^{24-26}$ Recently, room temperature ionic liquids are promising as new $\mathrm{CO}_{2}$ separation media because ionic liquids generally show preferential solubility for $\mathrm{CO}_{2}$ over other light gases. ${ }^{27-29}$ Further, the nonvolatile nature of ionic liquids prevents solvent loss because of evaporation during separation process compared with conventional liquid membranes. To incorporate excellent features of ionic liquids into polymer membranes, some imidazolium salt-containing polymers have been studied. ${ }^{30-34}$ However, their $\mathrm{CO}_{2}$ permeability is relatively low. The low permeability is expected to be overcome through the introduction of imidazolium salts into high-gaspermeable poly(diphenylacetylene).

Sulfonated polymers have been synthesized to develop proton exchange membrane materials. ${ }^{35-41}$ They have such strong polar groups, sulfonic acid groups, that they are also expected to show high $\mathrm{CO}_{2}$ permselectivity. However, most of the sulfonated polymers were designed for fuel cell, and thus they were not gas-permeable polymers. Some sulfonated polyimides containing hexafluoroisopropylidene linkage were synthesized to develop high $\mathrm{CO}_{2}$-permeable separation membranes, and they are reported to show high $\mathrm{CO}_{2}$ permselectivity and relatively high $\mathrm{CO}_{2}$ permeability. ${ }^{41}$

In the present study, we synthesized novel poly(diphenylacetylene)s having silanol groups, imidazolium salts and sulfonic acid groups in the side chains (Scheme 1). First, we synthesized diphenylacetylene monomer having a phenoxysilyl group and performed metathesis polymerization of the monomer. Silanol-containing polymer was obtained by the decomposition of phenoxysilyl groups in the polymer. ${ }^{42}$ Second, poly(diphenylacetylene) having bromoethoxy groups was synthesized, and the membranes of poly(diphenylacetylene) having imidazolium salts was obtained by substitution reaction to the polymer membranes. ${ }^{43}$ Finally, sulfonated poly(diphenylacetylene)s was synthesized by sulfonation of poly(diphenylacetylene)s bearing trimethylsilyl and $t$-butyl groups. ${ }^{44,45}$

\section{EXPERIMENTAL PROCEDURE}

\section{Measurements}

The molecular weights and polydispersity ratios of polymers were estimated by gel permeation chromatography (THF as eluent, polystyrene calibration) at $40{ }^{\circ} \mathrm{C}$ on a Shimadzu LC-10AD chromatograph (Shimadzu Co., Kyoto, Japan) equipped with three polystyrene gel columns (Shodex KF- $802.5 \times 1$ and A-80M $\times 2$ ) and a Shimadzu RID-6A refractive index detector (Shimadzu Co.). IR spectra were recorded on a Nicolet MAGNA 560 spectrometer (Hitachi High-Technologies Co., Tokyo, Japan). Thermogravimetric analyses were conducted with Rigaku TG-DTA 8078G1 (Rigaku Co., Tokyo, Japan) under $\mathrm{N}_{2}$ at a $10{ }^{\circ} \mathrm{C} \mathrm{min}^{-1}$ heating rate. Gas permeability coefficients of polymer membranes were measured with a Tsukubarikaseiki K-315-N gas permeability apparatus (Tsukubarikaseiki Co., Ibaraki, Japan) at $25^{\circ} \mathrm{C}$ under $1 \mathrm{~atm}$ upstream pressure. The permeability coefficient $P$ expressed in the unit of barrer ( 1 barrer $=10^{-10} \mathrm{~cm}^{3}$ (STP) $\mathrm{cm} \mathrm{cm}^{-2} \mathrm{~s}^{-1}$ $\mathrm{cm} \mathrm{Hg}^{-1}$ ) was calculated from the slope of the steady-state line. The $D$ value was determined by the time lag method using the following equation:

$$
D=l^{2} / 6 \theta
$$

where $l$ is the membrane thickness and $\theta$ is the time lag, which is given by the intercept of the asymptotic line of time-pressure curve to the time axis. The $S$ value was calculated by using equation $S=P / D$.

\section{Materials}

Toluene as a polymerization solvent was purified by distillation over calcium hydride. $\mathrm{TaCl}_{5}$ (Aldrich, Tokyo, Japan; 99.999\%), as a main catalyst, was used without further purification, whereas $n-\mathrm{Bu}_{4} \mathrm{Sn}$ as a cocatalyst was purified by distillation. The procedures of synthesis of acetylene monomers and polymer reactions were referring to the previous reports. ${ }^{42-45}$

\section{Polymerization}

Polymerization was carried out in a glass tube equipped with a three-way stopcock at $80^{\circ} \mathrm{C}$ for $24 \mathrm{~h}$ under dry nitrogen. A polymerization procedure is as follows: the monomer solution was prepared in a glass tube. Another glass tube was charged with $\mathrm{TaCl}_{5}, n-\mathrm{Bu}_{4} \mathrm{Sn}$ and toluene; this catalyst solution was aged at $80^{\circ} \mathrm{C}$ for $10 \mathrm{~min}$, and then the monomer solution was added to it. Polymerization was run at $80^{\circ} \mathrm{C}$ for $24 \mathrm{~h}$, which was quenched with a small amount of methanol. The obtained polymer was isolated by precipitation into a large excess of methanol, and its yield was determined gravimetrically.

\section{Membrane fabrication}

Membranes (thickness $50-60 \mu \mathrm{m}$ ) of polymers $\mathbf{2 a}$ and $\mathbf{2} \mathbf{b}$ were prepared by casting their toluene solutions (conc. $0.1-0.2 \mathrm{wt} \%$ ) into glass plates. Membranes (thickness $80-120 \mu \mathrm{m}$ ) of polymers $\mathbf{3} \mathbf{c}$ and $\mathbf{3 d}$ were prepared by casting their methanol solutions (conc. $0.2-0.3 \mathrm{wt} \%$ ) into polytetrafluoroethylene plates. The plate was covered with a glass vessel to slow solvent evaporation (3-5 days). After a membrane was formed, the membrane was peeled off and dried to constant weight under atmospheric pressure at room temperature.

\section{Decomposition of phenoxysilyl group}

The decomposition of siloxy groups in polymer membrane was carried out using a solution of $n-\mathrm{Bu}_{4} \mathrm{~N}^{+} \mathrm{F}^{-}$in dimethylformamide. A detailed procedure is as follows: the membrane of $\mathbf{2 a}(0.097 \mathrm{~g}, 0.21 \mathrm{mmol}$ repeating unit) was put into a flask, and then flushed with nitrogen. Another flask was charged with $n-$ $\mathrm{Bu}_{4} \mathrm{~N}^{+} \mathrm{F}^{-}(0.55 \mathrm{~g}, 2.1 \mathrm{mmol})$, and then it was dried under reduced pressure at $45{ }^{\circ} \mathrm{C}$ for $48 \mathrm{~h}$. A dried dimethylformamide $(20 \mathrm{ml})$ was added into the flask under nitrogen, and then the $n-\mathrm{Bu}_{4} \mathrm{~N}^{+} \mathrm{F}^{-}$solution was added to the flask in which the membrane was placed. The decomposition reaction was carried out at room temperature for $72 \mathrm{~h}$ under nitrogen. Then, the membrane was immersed in a mixture of methanol/water (9/1) for $6 \mathrm{~h}$, followed by in methanol for $24 \mathrm{~h}$. The membrane was dried at room temperature under atmospheric pressure for $24 \mathrm{~h}$.

\section{Substitution of 1-methylimidazole}

The reaction was carried out at $60^{\circ} \mathrm{C}$ using an excess of 1-methylimidazole. A detailed procedure is as follows: a polymer membrane $(\mathrm{ca} .0 .10 \mathrm{~g})$ was put into a flask. A mixture of 1-methylimidazole $(7.0 \mathrm{ml})$ and $\mathrm{CH}_{3} \mathrm{CN}(43 \mathrm{ml})$ was poured into the flask, and the flask was heated at $60^{\circ} \mathrm{C}$. After $24 \mathrm{~h}$, the membrane was washed by methanol, and then immersed in methanol for $24 \mathrm{~h}$

\section{Exchange of counteranions}

The reaction was carried out at room temperature using an excess of $\mathrm{CF}_{3} \mathrm{COOK}$ and $\left(\mathrm{CF}_{3} \mathrm{SO}_{2}\right)_{2} \mathrm{NLi}$. A detailed procedure is as follows: a polymer membrane $(\mathrm{ca} .0 .10 \mathrm{~g})$ was put into a flask. A mixture of $\mathrm{CF}_{3} \mathrm{COOK}(1.0 \mathrm{~g})$ and methanol $(50 \mathrm{ml})$ was poured into the flask at room temperature. After $24 \mathrm{~h}$, the membrane was washed by methanol, and then immersed in methanol for $24 \mathrm{~h}$.

\section{Sulfonation}

Before the polymer sulfonation, acetyl sulfate was prepared by the reaction of acetic anhydride and sulfuric acid in $\mathrm{CHCl}_{3}$. In a typical sulfonation, polymer 2c $(0.12 \mathrm{~g})$ was dissolved in $20 \mathrm{ml}$ of $\mathrm{CHCl}_{3}$ and purged with nitrogen. The polymer solution was stirred at $40^{\circ} \mathrm{C}$, and acetyl sulfate solution prepared as described above was then slowly added to it. The reaction was terminated after $1 \mathrm{~h}$ by precipitating in a large amount of THF. The precipitation was washed several times with THF. The obtained polymer was dried in a vacuum at room 


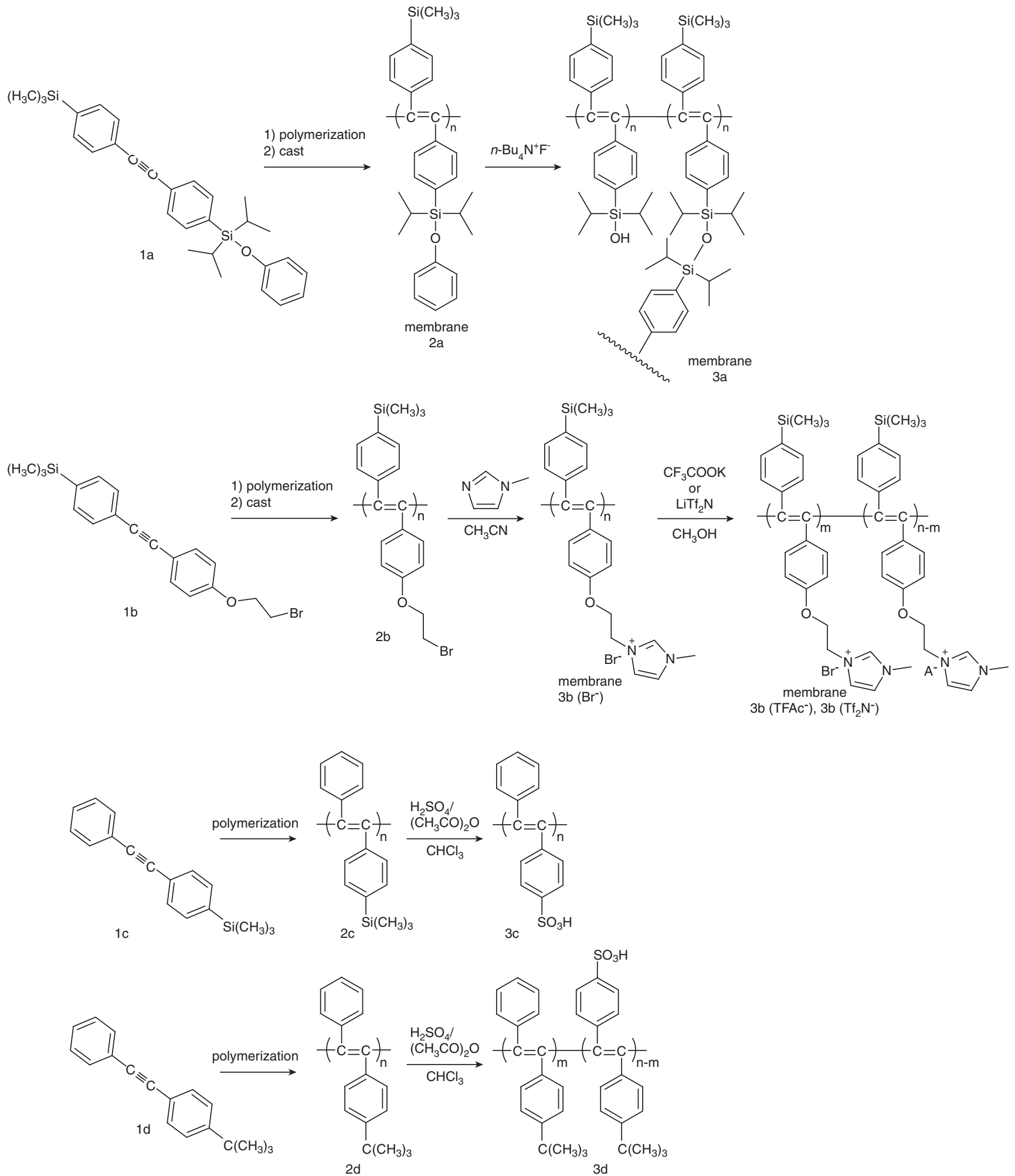

Scheme 1 Synthesis of poly(diphenylacetylene) having various polar groups.

temperature for $24 \mathrm{~h}$. The product was characterized by Fourier transforminfrared spectroscopy, and the degree of sulfonation was calculated by chemical titration: a polymer sample $(0.10 \mathrm{~g})$ was dissolved in $100 \mathrm{ml}$ of methanol and the solution was titrated with $0.05 \mathrm{moll}^{-1}$ ethanolic potassium hydroxide or $0.05 \mathrm{moll}^{-1}$ aqueous potassium hydroxide using $\mathrm{pH}$ instrument.

\section{RESULTS AND DISCUSSION}

\section{Polymerization}

The polymerizations of acetylene monomers $\mathbf{1 a}-\mathbf{d}$ were carried out using $\mathrm{TaCl}_{5} / n-\mathrm{Bu}_{4} \mathrm{Sn}$ catalyst in toluene at $80^{\circ} \mathrm{C}$. The results of polymerizations are summarized in Table 1 . Monomers $\mathbf{1 a}$ and $\mathbf{1 b}$ 
Table 1 Polymerizations of $1 \mathrm{a}-\mathrm{d}$ with $\mathrm{TaCl}_{5} / n-\mathrm{Bu}_{4} \mathrm{Sn}^{\mathrm{a}}$

\begin{tabular}{lcccc}
\hline & & \multicolumn{3}{c}{ Polymer ${ }^{\mathrm{b}}$} \\
\cline { 3 - 5 } Monomer & {$[\mathrm{M}]_{0}(\mathrm{M})$} & Yield (\%) & $\mathrm{M}_{w}{ }^{\mathrm{c}}$ & $\mathrm{M}_{w} \mathrm{M}_{n}{ }^{\mathrm{c}}$ \\
\hline 1a & 0.20 & 62 & 931000 & 2.47 \\
1b & 0.20 & 66 & 1110000 & 2.62 \\
1c & 0.50 & 93 & 7370000 & 3.30 \\
1d & 0.50 & 90 & 2220000 & 3.42 \\
\hline
\end{tabular}

Abbreviation: GPC, gel permeation chromatography.

aln toluene at $80^{\circ} \mathrm{C}$ for $24 \mathrm{~h} ;\left[\mathrm{TaCl}_{5}\right]=20 \mathrm{~mm},\left[n-\mathrm{Bu}_{4} \mathrm{Sn}\right]=40 \mathrm{~mm}$

bToluene- and methanol-insoluble product.

cMeasured by GPC.

polymerized to afford the corresponding polymers $\mathbf{2} \mathbf{a}$ and $\mathbf{2} \mathbf{b}$ in good yields, whose weight-average molecular weights reached up to 931000 and 1110000 , respectively. A variety of poly(diphenylacetylene) derivatives have been synthesized by metathesis polymerization using $\mathrm{TaCl}_{5}$ catalyst so far, and most polymers have high molecular weights (>300 000), except ones having very bulky substituents. ${ }^{11,12}$ Novel acetylene monomers containing a phenoxysilyl group and a bromoethoxy group ( $\mathbf{1 a}$ and $\mathbf{1 b}$ ) polymerized similarly to other common diphenylacetylenes, suggesting that metathesis polymerizability of diphenylacetylene is hardly influenced by the functional groups of phenoxysilyl and bromoethoxy groups. The polymerizations of $\mathbf{1} \mathbf{c}$ and $\mathbf{1 d}$ provided the corresponding polymers (2c and 2d) with very high molecular weights in high yields, which is the same as the results reported previously. ${ }^{8,46}$ All the polymers (2ad) were totally soluble in toluene, $\mathrm{CHCl}_{3}$ and THF, whereas insoluble in hexane, dimethylformamide, dimethyl sulfoxide and methanol.

\section{Decomposition of phenoxysilyl groups}

Free-standing membrane of polymer $2 \mathbf{a}$ was prepared by casting polymer from the toluene solution. The decomposition of phenoxysilyl groups of membrane $2 \mathrm{a}$ was carried out using $n-\mathrm{Bu}_{4} \mathrm{~N}^{+} \mathrm{F}^{-}$in dimethylformamide at room temperature for $72 \mathrm{~h}$, which afforded membrane 3a bearing silanol groups. Figure 1 shows the IR spectra of 2a, 3a and diisopropyl(phenylethynylphenyl)silyl ether (model compound). The IR spectrum of $2 \mathbf{a}$ showed the absorption at $1150 \mathrm{~cm}^{-1}$ assigned to the asymmetric stretching of $\mathrm{Si}-\mathrm{O}-\mathrm{C}$ in the phenoxysilyl groups, whereas no absorption at $1150 \mathrm{~cm}^{-1}$ was observed in the spectrum of $3 \mathbf{a}$. The characteristic broad peak at $3400 \mathrm{~cm}^{-1}$ in the membrane after the phenoxysilyl decomposition is attributed to the $\mathrm{O}-\mathrm{H}$ stretching of the silanol groups. These results represent the completion of the decomposition of phenoxysilyl groups and the generation of silanol. The absorption at $1050 \mathrm{~cm}^{-1}$ derived from $\mathrm{Si}-\mathrm{O}-\mathrm{Si}$ bond appeared after the phenoxysilyl decomposition, which indicates that some silanol groups would form $\mathrm{Si}-\mathrm{O}-\mathrm{Si}$ bonds through hydrolysis.

The content of $\mathrm{Si}-\mathrm{O}-\mathrm{Si}$ bonds was calculated from the peak strength at $1050 \mathrm{~cm}^{-1}$ on the basis of the peak at $1380 \mathrm{~cm}^{-1}$ attributed to $\mathrm{Si}-\mathrm{C}-\mathrm{H}$ bending. Figure 1 shows the spectrum of diisopropyl(phenylethynylphenyl)silyl ether, which was used as a model compound containing $100 \%$ of $\mathrm{Si}-\mathrm{O}-\mathrm{Si}$ bonds. It was found that membrane $3 \mathbf{a}$ included $20 \%$ of $\mathrm{Si}-\mathrm{O}-\mathrm{Si}$ bonds.

Substitution of 1-methylimidazole and exchange of counteranions First, the substitution reaction of 1-methylimidazole to polymer $\mathbf{2 b}$ was carried out in $\mathrm{CHCl}_{3}$ solution. The polymer precipitated as the reaction proceeded, and the obtained polymer did not completely dissolve in any solvents. The insolubility of the polymer is a problem for the

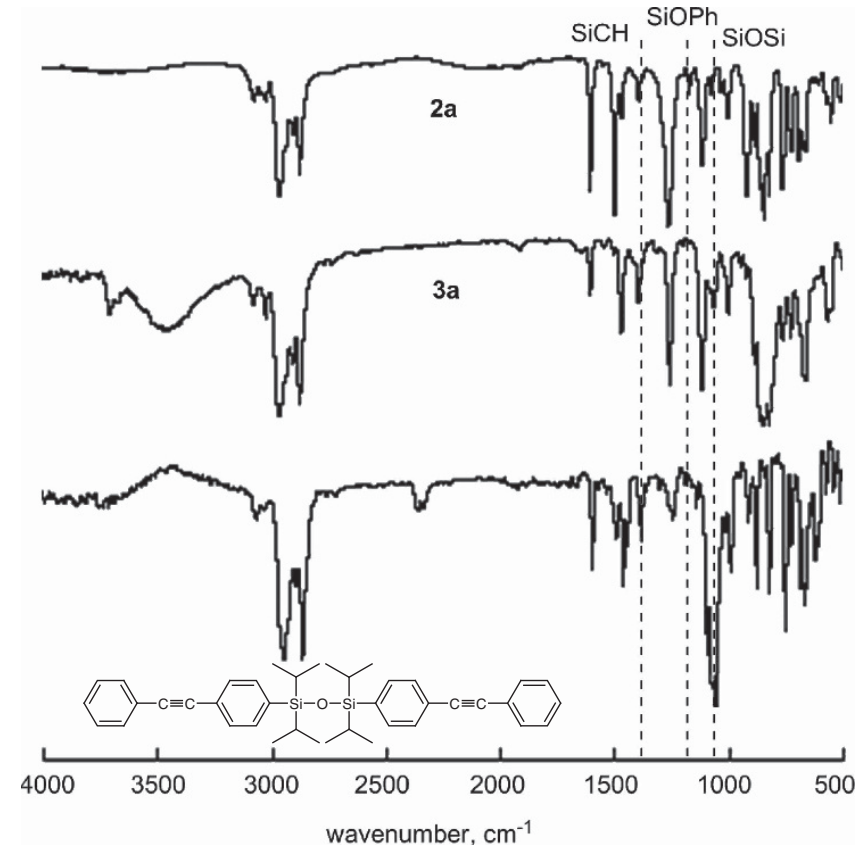

Figure $\mathbf{1}$ Infrared spectroscopy (IR) spectra of the membranes of $\mathbf{2 a}, \mathbf{3} \mathbf{a}$ and diisopropyl(phenylethynylphenyl)silyl ether.

preparation of membrane. Next, the membrane of polymer $\mathbf{2} \mathbf{b}$ was prepared by solution casting, and the substitution reaction was carried out in the membrane state. Figure 2 shows the IR spectra of membranes before and after the substitution reaction, that is, membranes of $\mathbf{2} \mathbf{b}$ and $\mathbf{3 b}\left(\mathrm{Br}^{-}\right)$. The IR spectrum of $\mathbf{2 b}$ showed two absorptions at $c a .1600$ and $1500 \mathrm{~cm}^{-1}$ assignable to the stretchings of conjugated $\mathrm{C}-\mathrm{C}$ bonds in the aromatic rings. After substitution reaction, the spectrum of polymer $3 \mathbf{b}\left(\mathrm{Br}^{-}\right)$showed another absorption around $1600 \mathrm{~cm}^{-1}$ besides the two peaks of aromatic rings. The absorption is assigned to heterocyclic ring, which suggests that 1-methylimidazole was substituted to poly(diphenylacetylene).

To determine the degree of substitution, the content of nitrogen atom was measured by elemental analysis. The content of nitrogen for 3b $\left(\mathrm{Br}^{-}\right)$was $5.90 \%$, whereas the content should be $6.12 \%$ if the bromoethoxy group was quantitatively converted to the imidazolium salt. From the result of elemental analysis, the degree of substitution for $\mathbf{3 b}\left(\mathrm{Br}^{-}\right)$was determined to be as high as 0.96 .

Figure 2 shows the spectra of membranes before and after anion exchange reaction. In the spectrum of $3 \mathbf{b}\left(\mathrm{TFAc}^{-}\right)$, the absorption at $1700 \mathrm{~cm}^{-1}$ characteristic of $\mathrm{C}=\mathrm{O}$ and the absorption at $1200 \mathrm{~cm}^{-1}$ because of $\mathrm{C}-\mathrm{F}$ bond were observed, whereas the spectrum of $\mathbf{3 b}$ $\left(\mathrm{Br}^{-}\right)$does not show such absorptions. In the spectrum of $\mathbf{3 b}$ $\left(\mathrm{Tf}_{2} \mathrm{~N}^{-}\right)$, the absorption at $1200 \mathrm{~cm}^{-1}$ assigned to $\mathrm{C}-\mathrm{F}$ bond and the absorptions at 1400 and $1050 \mathrm{~cm}^{-1}$ assigned to $\mathrm{S}=\mathrm{O}$ were observed. These results suggest that the anion exchange reactions proceeded and afforded polymer membranes having $\mathrm{TFAc}^{-}$and $\mathrm{Tf}_{2} \mathrm{~N}^{-}$as counteranions. According to elemental analyses, the contents of fluorine atom for $\mathbf{3 b}\left(\mathrm{TFAc}^{-}\right)$and $\mathbf{3 b}\left(\mathrm{Tf}_{2} \mathrm{~N}^{-}\right)$were $9.83 \%$ and $15.95 \%$, respectively. When the exchange reactions proceed quantitatively, the contents of fluorine atom for $\mathbf{3 a}\left(\mathrm{TFAc}^{-}\right)$and $\mathbf{3 a}\left(\mathrm{Tf}_{2} \mathrm{~N}^{-}\right)$should be $11.31 \%$ and $16.98 \%$, respectively. Thus, the conversions of $\mathrm{Br}^{-}$to the desired anions were calculated as $87 \%$ and $94 \%$, respectively. There is not much difference between the conversions of TFAc $^{-}$and $\mathrm{Tf}_{2} \mathrm{~N}^{-}$. Anionic species is generally stabilized by electron-withdrawing group, which may affect the anion exchange reaction. 


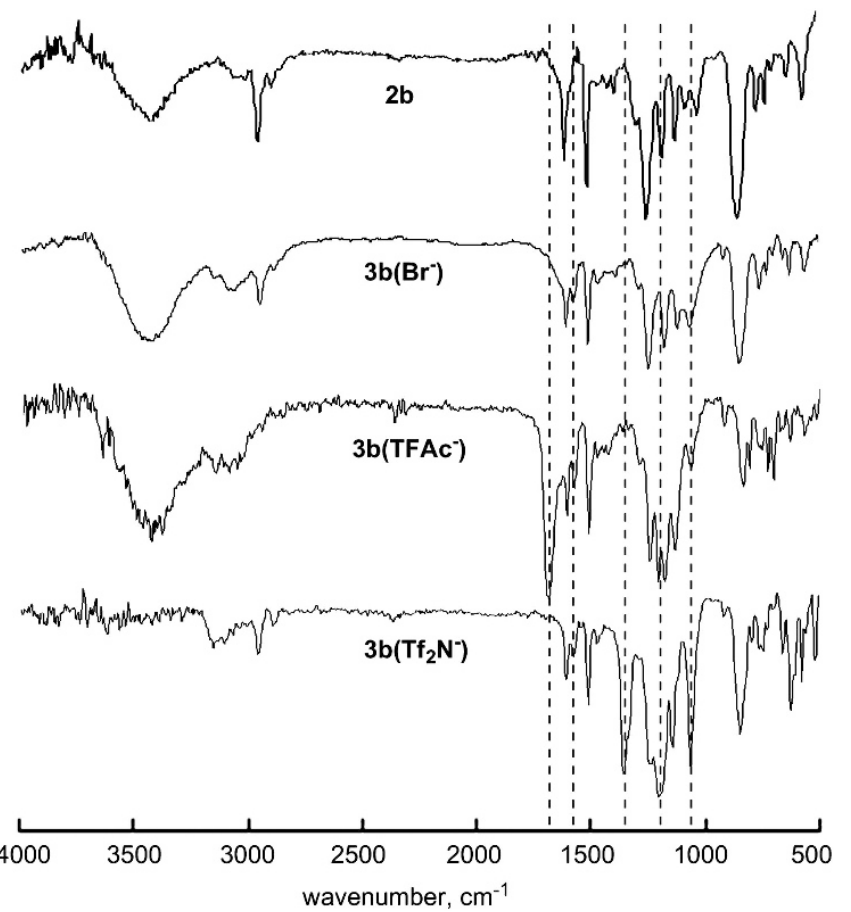

Figure 2 Infrared spectroscopy (IR) spectra of the membranes of $\mathbf{2 b}, \mathbf{3 b}$ $\left(\mathrm{Br}^{-}\right), 3 \mathbf{b}\left(\mathrm{TFAc}^{-}\right)$and $3 \mathbf{b}\left(\mathrm{Tf}_{2} \mathrm{~N}^{-}\right)$.

\section{Sulfonation}

Figure 3 depicts the IR spectra of polymers $(2 \mathrm{c}$ and $2 \mathrm{~d})$ and their sulfonated polymers ( $\mathbf{3 c}$ and $\mathbf{3 d}$ ). The spectrum of $\mathbf{3 c}$ showed the broad absorption at $1200 \mathrm{~cm}^{-1}$ and the two sharp absorptions at 1060 and $1050 \mathrm{~cm}^{-1}$, which were not observed in the spectrum of $2 \mathrm{c}$. In general, sulfonic acid $\left(\mathrm{SO}_{3} \mathrm{H}\right)$ shows absorptions at 1350 and $1150 \mathrm{~cm}^{-1}$, and sulfonic acid monohydrate $\left(\left[\mathrm{H}_{3} \mathrm{O}\right]^{+}\left[\mathrm{SO}_{3}\right]^{-}\right)$shows an absorption at $1200 \mathrm{~cm}^{-1} .47$ Therefore, it is thought that polymer $3 \mathbf{c}$ has the sulfonic acid groups as $\left[\mathrm{H}_{3} \mathrm{O}\right]^{+}\left[\mathrm{SO}_{3}\right]^{-}$rather than $\mathrm{SO}_{3} \mathrm{H}$. The spectrum of $\mathbf{3 c}$, in addition, showed the broad absorption in the range from 3700 to $3200 \mathrm{~cm}^{-1}$ derived from $\mathrm{OH}$ groups, which supports that polymer $3 \mathrm{c}$ contains sulfonic acid groups. The spectrum of $2 \mathrm{c}$ showed the absorptions at 850 and $810 \mathrm{~cm}^{-1}$ derived from the stretching of $\mathrm{Si}-\mathrm{CH}_{3}$, and the absorptions completely disappeared after sulfonation. These results indicate that sulfonic acid groups were substituted to trimethylsilyl groups. Same as in $\mathbf{3 c}$, the spectrum of $\mathbf{3 d}$ showed the absorptions at ca. 3500, 1200, 1060 and $1050 \mathrm{~cm}^{-1}$ because of $\mathrm{SO}_{3} \mathrm{H}$, indicating that the sulfonated polymer was successfully formed from polymer $\mathbf{2 d}$.

To determine the degree of sulfonation, the chemical titration was operated. The solutions of sulfonated polymers were titrated by $0.05 \mathrm{moll}^{-1}$ potassium hydroxide solution. From the titration, the degree of sulfonation values of $\mathbf{3} \mathbf{c}$ and $\mathbf{3 d}$ were estimated to be 1.01 and 0.83 , respectively.

\section{Thermal properties}

The thermal stability of all the polymers in the present study was examined by thermogravimetric analysis under $\mathrm{N}_{2}$ (Figure 4). Thermal decomposition temperature $\left(T_{\mathrm{d}}\right)$ of $2 \mathrm{a}$ was approximately $400{ }^{\circ} \mathrm{C}$, indicating good thermal stability. Polymer $\mathbf{2 b}$ also exhibited high thermal stability, but the decomposition started at $220^{\circ} \mathrm{C}$. This would be attributed to the dehydration of silanol groups. The $T_{\mathrm{d}}$ 's of $\mathbf{3 a}, \mathbf{3} \mathbf{b}$ $\left(\mathrm{Br}^{-}\right)$and $\mathbf{3 b}\left(\mathrm{Tf}_{2} \mathrm{~N}^{-}\right)$were over $300^{\circ} \mathrm{C}$, whereas that of $\mathbf{3 b}\left(\mathrm{TFAc}^{-}\right)$

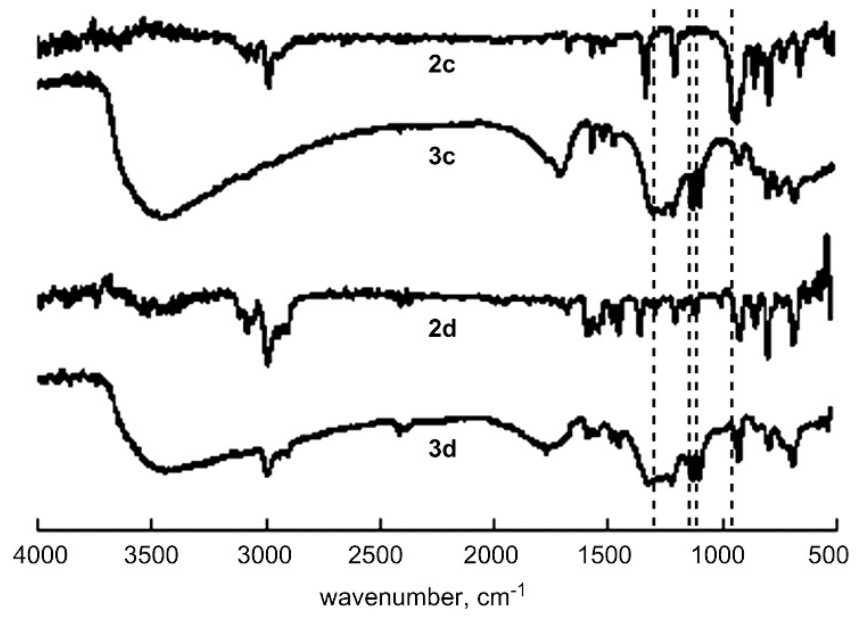

Figure $\mathbf{3}$ Infrared spectroscopy (IR) spectra of polymers $\mathbf{2 c}$ and $\mathbf{2 d}$ and the sulfonated polymers $\mathbf{3 c}$ and $\mathbf{3 d}$.

was as low as $180^{\circ} \mathrm{C}$. Polymers $2 \mathrm{c}$ and $2 \mathbf{d}$ showed high thermal stability, and their $T_{\mathrm{d}}$ 's were $430^{\circ} \mathrm{C}$. However, the $T_{\mathrm{d}}$ 's of the sulfonated polymers $3 \mathbf{c}$ and $3 \mathbf{d}$ were $200^{\circ} \mathrm{C}$ and $250{ }^{\circ} \mathrm{C}$, respectively. The decomposition of sulfonic acid groups would occur at relatively low temperature.

\section{Gas permeability}

The permeability of the membranes of $\mathbf{2} \mathbf{a}-\mathbf{d}$ and $\mathbf{3} \mathbf{a}-\mathbf{d}$ to various gases was examined at $25^{\circ} \mathrm{C}$ (Table 2 ). The permeability coefficients $(P)$ of 2a to oxygen, nitrogen and carbon dioxide were 12, 3.9 and 61 barrers, respectively, whose values are comparable with bulky silyl group-containing poly(diphenylacetylene)s reported previously. ${ }^{48-52}$ The phenoxysilyl decomposition of the membrane of $\mathbf{2 a}$ markedly increased the gas permeability, and the $P_{\mathrm{O} 2}, P_{\mathrm{N} 2}$ and $P_{\mathrm{CO} 2}$ of the membrane of $\mathbf{3 a}$ were 1300, 770 and 4300 barrers, respectively. This is supported by the decrease of membrane density $\left(1.09 \mathrm{~g} \mathrm{~cm}^{-3}\right.$ for $2 \mathrm{a}$ and $0.887 \mathrm{~g} \mathrm{~cm}^{-3}$ for $\left.3 \mathrm{a}\right)$. It was expected that the polar silanol groups makes the membrane dense owing to their interaction. The decomposition was carried out at a solid state, and partial crosslinking was formed during the reaction. Therefore, the polymer chain packing was inhibited even though polar silanol groups were generated. It is noteworthy that the permeability of $\mathbf{3 a}$ is one of the highest among all the known polymers bearing polar groups. ${ }^{53}$

The $P_{\mathrm{O} 2}, P_{\mathrm{N} 2}$ and $P_{\mathrm{CO} 2}$ of polymer $2 \mathbf{b}$ were 46,16 and 250 barrers, respectively. Compared with poly(1-trimethylsilyl-1-propyne) and poly(1-(p-trimethylsilyl)phenyl-2-phenylacetylene)), polymer $\mathbf{2 b}$ exhibited low gas permeability, which can be attributed to the flexible bromoethoxy group. It is known that high gas permeability of poly(substituted acetylene)s is in many cases based on spherical substituents, whereas the presence of long flexible side chains either hardly affects gas permeability or rather decreases it. ${ }^{10}$ The substitution reaction of 1-methylimidazole caused a decrease in gas permeability and a pronounced increase in $\mathrm{CO}_{2}$ permselectivity. The decrease in gas permeability was originated from the decrease of diffusion and solubility coefficients (Table 3 ). These decreases are considered because the intermolecular interaction is strengthened by polar imidazolium salts. The $\mathrm{CO}_{2} / \mathrm{N}_{2}$ separation factor $\left(P_{\mathrm{CO} 2} / P_{\mathrm{N} 2}\right)$ of $3 \mathbf{b}\left(\mathrm{Br}^{-}\right)$was 44 , which is much larger than that of $\mathbf{2 b}\left(P_{\mathrm{CO} 2} /\right.$ $\left.P_{\mathrm{N} 2}=16\right)$. The diffusivity selectivity $\left(D_{\mathrm{CO} 2} / D_{\mathrm{N} 2}\right)$ of $3 \mathbf{b}\left(\mathrm{Br}^{-}\right)$and $\mathbf{2} \mathbf{b}$ were 0.70 and 0.92 , respectively, indicating that imidazolium salts in poly(diphenylacetylene) do not critically affect diffusivity selectivity. 

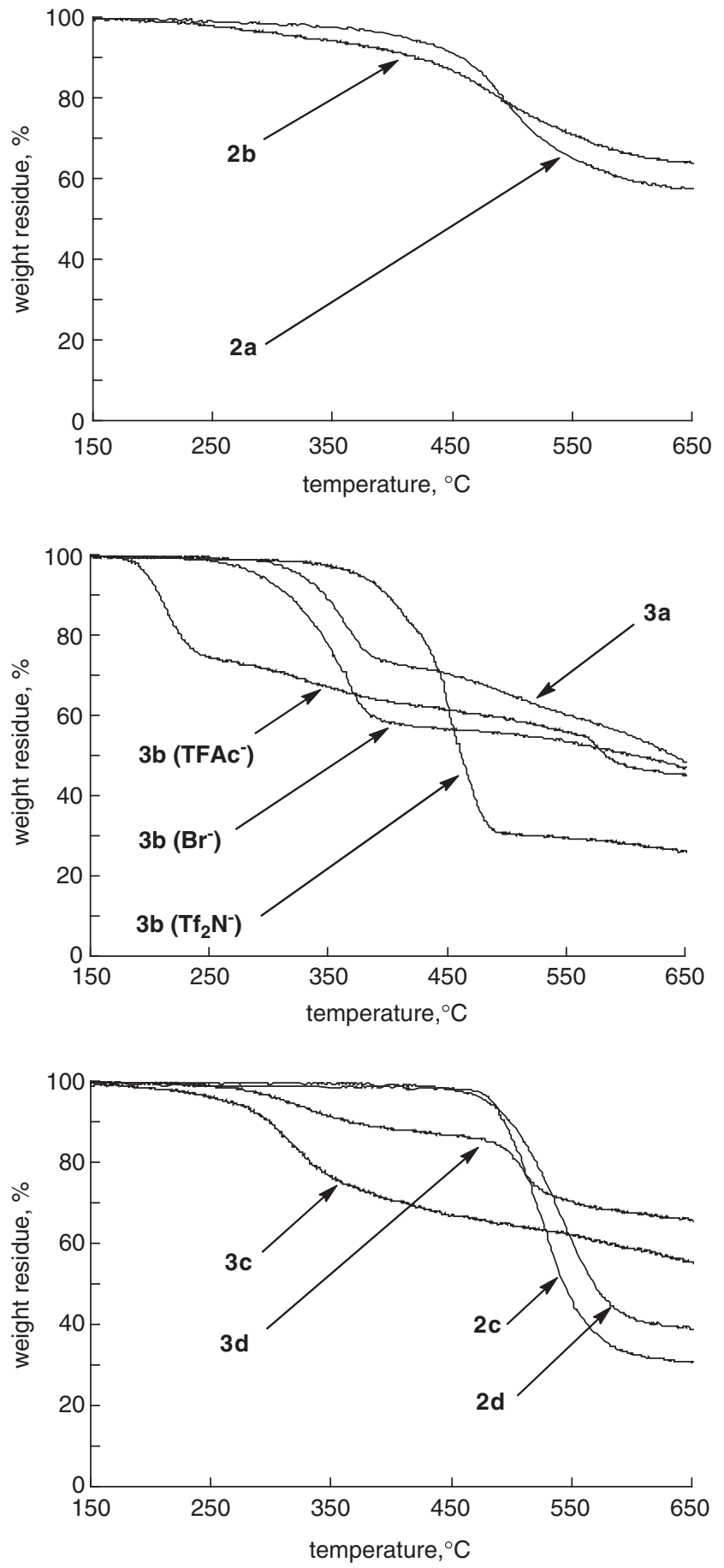

Figure 4 Thermogravimetric analysis (TGA) thermograms of the present polymers under $\mathrm{N}_{2}$.

On the other hand, the $S_{\mathrm{CO} 2} / S_{\mathrm{N} 2}$ of $\mathbf{3 b}\left(\mathrm{Br}^{-}\right)$and $\mathbf{2 b}$ were 66 and 17 , respectively, which manifests that the solubility selectivity $\left(S_{\mathrm{CO} 2} / S_{\mathrm{N} 2}\right)$ is largely enhanced by substitution of 1 -methylimidazole to poly (diphenylacetylene). Thus, the significant increase in the $\mathrm{CO}_{2}$ permselectivity is based on solubility selectivity, which is, in turn, attributable to the strong interaction of the imidazolium salt with the $\mathrm{CO}_{2}$ molecule.

The exchange of counteranions to bulkier ones resulted in increases of gas permeability. Thus, the $P_{\mathrm{CO} 2}$ values of $\mathbf{3 b}\left(\mathrm{TFAc}^{-}\right)$
Table 2 Gas permeability coefficients and separation factors of membranes

\begin{tabular}{lccccc}
\hline Membrane & $P_{\mathrm{O} 2}{ }^{\mathrm{a}}$ & $P_{\mathrm{N} 2}{ }^{\mathrm{a}}$ & $P_{\mathrm{CO} 2}{ }^{\mathrm{a}}$ & $P_{\mathrm{O} 2} / P_{\mathrm{N} 2}$ & $P_{\mathrm{CO} 2} / P_{\mathrm{N} 2}$ \\
\hline 2a & 26 & 7.8 & 130 & 3.3 & 17 \\
3a & 1300 & 770 & 4300 & 1.7 & 5.6 \\
2b & 46 & 16 & 250 & 2.9 & 16 \\
3b $\left(\mathrm{Br}^{-}\right)$ & 1.5 & 0.25 & 11 & 6.0 & 44 \\
3b $\left(\mathrm{TFAc}^{-}\right)$ & 3.2 & 0.67 & 23 & 4.8 & 34 \\
3b $\left(\mathrm{Tf}_{2} \mathrm{~N}^{-}\right)$ & 6.3 & 1.7 & 53 & 3.7 & 31 \\
2c & 1800 & 960 & 6700 & 1.9 & 7.0 \\
3c & 0.63 & 0.072 & 3.9 & 8.8 & 54 \\
2d & 2100 & 890 & 6500 & 2.4 & 7.3 \\
3d & 31 & 6.0 & 180 & 5.2 & 30 \\
\hline
\end{tabular}

Abbreviation: STP, standard temperature and pressure.

aln the unit of barrer ( 1 barrer $=1 \times 10^{-10} \mathrm{~cm}^{3}(\mathrm{STP}) \mathrm{cm} \mathrm{cm}^{-2} \mathrm{~s}^{-1} \mathrm{~cm} \mathrm{Hg}^{-1}$ ),

Table 3 Gas diffusion and solubility coefficients

\begin{tabular}{lcccccc}
\hline & $D_{\mathrm{N} 2}{ }^{\mathrm{a}}$ & $D_{\mathrm{CO} 2}{ }^{\mathrm{a}}$ & $D_{\mathrm{CO} 2} / D_{\mathrm{N} 2}$ & $S_{\mathrm{N} 2}{ }^{\mathrm{b}}$ & $S_{\mathrm{CO} 2}{ }^{\mathrm{b}}$ & $S_{\mathrm{CO} 2} / S_{\mathrm{N} 2}$ \\
\hline 2b & 78 & 72 & 0.92 & 2.1 & 35 & 17 \\
3b $\left(\mathrm{Br}^{-}\right)$ & 6.3 & 4.4 & 0.70 & 0.37 & 24 & 65 \\
3b $\left(\mathrm{TFAc}^{-}\right)$ & 6.8 & 5.1 & 0.75 & 0.99 & 45 & 45 \\
3b $\left(\mathrm{Tf}_{2} \mathrm{~N}^{-}\right)$ & 21 & 18 & 0.86 & 0.81 & 29 & 36 \\
\hline
\end{tabular}

Abbreviation: STP, standard temperature and pressure.

aln the units of $1 \times 10^{-8} \mathrm{~cm}^{2} \mathrm{~s}^{-1}$.

bIn the units of $1 \times 10^{-3} \mathrm{~cm}^{3}(\mathrm{STP}) \mathrm{cm}^{-3} \mathrm{~cm} \mathrm{Hg}$.

and $\mathbf{3 b}\left(\mathrm{Tf}_{2} \mathrm{~N}^{-}\right)$were 23 and 53 barrers, respectively. For instance, TFAc ${ }^{-}$is bulkier than $\mathrm{Br}^{-}$, and the polymer chain packing is thought to be looser with the TFAc ${ }^{-}$counteranion owing to steric effect. $\mathrm{Tf}_{2} \mathrm{~N}^{-}$is an even bulkier counteranion, and $3 \mathbf{b}\left(\mathrm{Tf}_{2} \mathrm{~N}^{-}\right)$ exhibited the highest permeability among the imidazolium saltcontaining polymers. The $\mathrm{CO}_{2} / \mathrm{N}_{2}$ permselectivity and solubility selectivity gradually decreased as the bulkiness of the counteranion increased. This is because the bulkier counteranions weaken the effect of the ionic functionality.

The gas permeability coefficients of membranes before sulfonation (2c and 2d) were almost the same as the data reported in previous papers; ${ }^{9,42}$ poly(diphenylacetylene)s bearing spherical bulky trimethylsilyl or $t$-butyl groups exhibited high gas permeability. Sulfonation of poly(diphenylacetylene)s led to a significant decrease of gas permeability. For instance, the $P_{\mathrm{O} 2}, P_{\mathrm{N} 2}$ and $P_{\mathrm{CO} 2}$ values of $3 \mathrm{c}$ were $0.63,0.072$ and 3.9 barrers, respectively, which are three or four orders of magnitude smaller than those of $2 \mathrm{c}$. The decrease of gas permeability upon sulfonation can be accounted for by the strong intermolecular interaction between high polar sulfonic acid groups. In contrast, the $P_{\mathrm{CO} 2} / P_{\mathrm{N} 2}$ of $3 \mathrm{c}$ was as high as 54 , which is the highest among the present polymers. The high $\mathrm{CO}_{2}$ permselectivity of sulfonated poly(diphenylacetylene)s is thought to be due to the increase in the solubility of $\mathrm{CO}_{2}$ into polymer matrix, because the $\mathrm{CO}_{2}$ molecule strongly interacts with sulfonic acid groups. Interestingly, polymer $\mathbf{3 d}$ exhibited relatively high gas permeability and possesses sulfonic acids. Polymer $\mathbf{3 d}$ has spherical bulky $t$-butyl groups even after sulfonation. The bulky substituents would prevent polymer chain packing by the steric repulsion. For the application to batteries and fuel cells, polymer materials that have both protonconducting and oxygen-permeable properties are desired. Therefore, polymer $\mathbf{3 d}$ is an interesting material as polymer electrolytes for batteries and fuel cells. 


\section{CONCLUSIONS}

A novel polyacetylene has been developed to introduce functional groups into poly(diphenylacetylene)s. Poly(diphenylacetylene)s having silanol groups were obtained by treatment of the precursor polymers having phenoxysilyl groups with $n-\mathrm{Bu}_{4} \mathrm{~N}^{+} \mathrm{F}^{-}$. Membranes of silanol-functionalized poly(diphenylacetylene)s exhibited very high gas permeability. The $P_{\mathrm{O} 2}$ value of poly(diphenylacetylene) bearing both silanol groups and crosslinked siloxane moieties was 1300 barrers, whose value is the largest among all the substituted acetylene polymers with functional groups. Poly(diphenylacetylene)s having imidazolium salts were synthesized by substitution of 1-methylimidazole to bromoethoxy groups. Exchange of counteranions was achieved quantitatively, and poly(diphenylacetylene)s with $\mathrm{Br}^{-}$, $\mathrm{TFAc}^{-}$and $\mathrm{Tf}_{2} \mathrm{~N}^{-}$as counteranions was obtained. Membranes of imidazolium salt-containing poly(diphenylacetylene)s exhibited high $\mathrm{CO}_{2} / \mathrm{N}_{2}$ permselectivity $\left(P_{\mathrm{CO} 2} / P_{\mathrm{N} 2}=31-44\right)$ because of their high $\mathrm{CO}_{2} / \mathrm{N}_{2}$ solubility selectivity. Bulky counteranions prevented polymer chains from packing together, and thus the permeability coefficients of membranes became larger in the order of $\mathrm{Br}^{-}<\mathrm{TFAc}^{-}<\mathrm{Tf}_{2} \mathrm{~N}^{-}$. Poly(diphenylacetylene)s having sulfonic acid groups were successfully obtained using acetyl sulfate as a reactant. The sulfonated poly (diphenylacetylene) having $t$-butyl groups showed high permeability and high permselectivity for $\mathrm{CO}_{2}$. Sulfonation of poly(diphenylacetylene) having trimethylsilyl groups gave desilylated and sulfonated poly(diphenylacetylene), which displayed pretty high $\mathrm{CO}_{2}$ permselectivity.

\section{ACKNOWLEDGEMENTS}

We are grateful to NOF Corporation (Tokyo, Japan) for supplying p-trimethylsilylphenylacetylene and p-trimethylsilylphenyl-2-phenylacetylene. This research was partly supported by a grant-in-aid for scientific research from the Ministry of Education, Science, Culture and Sports, Japan (No. 25810071).

1 Yampolskii, Y. U. Polymeric gas separation membranes. Macromolecules 45, 3298-3311 (2012).

2 Nagai, K., Lee, Y.-M. \& Masuda, T. in Macromolecular Engineering (eds. Matyjaszewsky, K., Gnanou, Y. \& Leibler, L.) Part 4, Ch. 19 (Wiley-VCH, Weinheim, Germany, 2007).

3 Masuda, T. \& Nagai, K. in Materials Science of Membranes (eds Yampolskii, Y. U., Pinnau, I. \& Freeman, B. D.) Ch. 8. (Wiley, Chichester, UK, 2006).

4 Ulbricht, M. Advanced functional polymer membranes. Polymer (Guildf) 47, 2217-2262 (2006).

5 Aoki, T., Kaneko, T. \& Teraguchi, M. Synthesis of functional $\pi$ conjugated polymers from aromatic acetylenes. Polymer (Guildf) 47, 4867-4892 (2006).

6 Masuda, T., Isobe, E., Higashimura, T. \& Takada, K. Poly[1-(trimethylsilyl)-1-propyne]: a new high polymer synthesized with transition metal catalysts and characterized by extremely high gas permeability. J. Am. Chem. Soc. 105, 7473-7474 (1983).

7 Tsuchihara, K., Masuda, T. \& Higashimura, T. Tractable silicon-containing poly(diphenylacetylenes): their synthesis and high gas permeability. J. Am. Chem. Soc. 113, 8548-8589 (1991).

8 Tsuchihara, K., Masuda, T. \& Higashimura, T. Polymerization of silicon-containing diphenylacetylenes and high gas permeability of the product polymers. Macromolecules 25, 5816-5820 (1992).

9 Sakaguchi, T., Yumoto, K., Shiotsuki, M., Sanada, F., Yoshikawa, M. \& Masuda, T. Synthesis of poly(diphenylacetylene) membranes by desilylation of various precursor polymers and their properties. Macromolecules 38, 2704-2709 (2005).

10 Nagai, K., Masuda, T., Nakagawa, T., Freeman, B. D. \& Pinnau, I. Poly[1-(trimethylsilyl)-1-propyne] and related polymers: synthesis, properties, and functions. Prog. Polym. Sci. 26, 721-798 (2001).

11 Shiotsuki, M., Sanda, F. \& Masuda, T. Polymerization of substituted acetylenes and features of the formed polymers. Polym. Chem. 2, 1044-1058 (2011).

12 Nomura, R. \& Masuda, T. in Encyclopedia of Polymer Science and Technology. 3rd edn (ed. Kroshwitz, J. I.) Vol. IA, p 1 (Wiley, New York, NY, USA, 2003).

13 Sakaguchi, T., Yumoto, K., Shida, Y., Shiotsuki, M., Sanda, F. \& Masuda, T. Synthesis, properties, and gas permeability of novel poly(diarylacetylene) derivatives. J. Polym. Sci. Part A 44, 5028-5038 (2006).
14 Lin, H. \& Freeman, B. D. Materials selection guidelines for membranes that remove $\mathrm{CO}_{2}$ from gas mixtures. J. Mol. Struct. 739, 57-74 (2005).

15 Shida, Y., Sakaguchi, T., Shiotsuki, M., Wagener, K. B. \& Masuda, T. Preparation and properties of polytolan membranes bearing $p$-hydroxyl groups. Polym. (Guildf) $46,1-4$ (2005).

16 Shida, Y., Sakaguchi, T., Shiotsuki, M., Sanda, F., Freeman, B. D. \& Masuda, T. Synthesis and properties of poly(diphenylacetylenes) having hydroxyl groups. Macromolecules 38, 4096-4102 (2005).

17 Shida, Y., Sakaguchi, T., Shiotsuki, M., Sanda, F., Freeman, B. D. \& Masuda, T. Synthesis and properties of membranes of poly(diphenylacetylenes) having fluorines and hydroxyl groups. Macromolecules 39, 569-574 (2006).

18 Kanaya, T., Tsukushi, I., Kaji, K., Sakaguchi, T., Kwak, G. \& Masuda, T. Role of local dynamics in the gas permeability of glassy substituted polyacetylenes. a quasielastic neutron scattering study. Macromolecules 35, 5559-5564 (2002).

19 Kanaya, T., Teraguchi, M., Masuda, T. \& Kaji, K. Local mobility of substituted polyacetylenes measured by quasielastic neutron scattering and its relationship with gas permeability. Polymer (Guildf) 40, 7157-7161 (1999).

20 Walcarius, A. Electrochemical applications of silicon-based organic-inorganic hybrid materials. Chem. Mater. 13, 3351-3372 (2001).

21 Wen, J. \& Wilkes, G. L. Organic/inorganic hybrid network materials by the sol-gel approach. Chem. Mater. 8, 1667-1681 (1996)

22 Ogoshi, T. \& Chujo, Y. Synthesis of amorphous and nanostructured cationic polyacetylene/silica hybrids by using ionic interactions. Macromolecules 38, 9110-9116 (2005).

23 Uragami, T., Matsugi, H. \& Miyata, T. Pervaporation characteristics of organic-inorganic hybrid membranes composed of poly(vinyl alcohol-co-acrylic acid) and tetraethoxysilane for water/ethanol separation. Macromolecules 38, 8440-8446 (2005).

24 Huddleston, J. G., Visser, A. E., Reichert, W. M., Willauer, H. D., Broker, G. A. \& Rogers, R. D. Characterization and comparison of hydrophilic and hydrophobic room temperature ionic liquids incorporating the imidazolium cation. Green Chem. 3, 156164 (2001).

25 Earle, M. J. \& Seddon, K. R. Ionic liquids. green solvents for the future. Pure Appl. Chem. 72, 1391-1398 (2000).

26 Welton, T. Room-temperature ionic liquids. solvents for synthesis and catalysis. Chem. Rev. 99, 2071-2084 (1999).

27 Bara, J. E., Carlisle, T. K., Gabriel, C. J., Camper, D., Finotello, A., Gin, D. L. \& Noble, R. D. Guide to $\mathrm{CO}_{2}$ separations in imidazolium-based room-temperature ionic liquids. Ind. Eng. Chem. Res. 48, 2739-2751 (2009).

28 Scovazzo, P., Kieft, J., Finan, D. A., Koval, C., Dubois, D. \& Noble, R. D. Gas separations using non-hexafluorophosphate $\left[\mathrm{PF}_{6}{ }^{-}\right]$anion supported ionic liquid membranes. J. Membr. Sci. 238, 57-63 (2004).

29 Scovazzo, P., Camper, D., Kieft, J., Poshusta, J., Koval, C. \& Noble, R. D. Regular solution theory and $\mathrm{CO}_{2}$ solubility in room-temperature ionic liquids. Ind. Eng. Chem. Res. 43, 6855-6860 (2004).

30 Bara, J. E., Lessmann, S., Gabriel, C. J., Hatakeyama, E. S., Noble, R. D. \& Gin, D. L. Synthesis and performance of polymerizable room-temperature ionic liquids as gas separation membranes. Ind. Eng. Chem. Res. 46, 5397-5404 (2007).

31 Aoki, T., Marwanta, E., Nagoshi, T., Teraguchi, M. \& Kaneko, T. Substituted cispolyacetylene ionic liquid, their manufacture, and their free-standing membranes, carbon dioxide separation membranes, and membranes showing reversible color change by stretching. Japanese Patent JP2010163561A (2010).

32 Bara, J. E., Gabriel, C. J., Hatakeyama, E. S., Carlisle, T. K., Lessmann, S., Noble, R. D. \& Gin, D. L. Improving $\mathrm{CO}_{2}$ selectivity in polymerized room-temperature ionic liquid gas separation membranes through incorporation of polar substituents. J. Membr. Sci. 321, 3-7 (2008).

33 Carlisle, T. K., Bara, J. E., Lafrate, A. L., Gin, D. L. \& Noble, R. D. Main-chain imidazolium polymer membranes for $\mathrm{CO}_{2}$ separations: an initial study of a new ionic liquid-inspired platform. J. Membr. Sci. 359, 37-43 (2010).

$34 \mathrm{Gu}$, Y. \& Lodge, T. P. Synthesis and gas separation performance of triblock copolymer ion gels with a polymerized ionic liquid mid-block. Macromolecules 44, 1732-1736 (2011).

35 Genies, C. Mercier, R., Sillion, B. Cornet, N. Gebel, G. \& Pineri, M. Soluble sulfonated naphthalenic polyimides as materials for proton exchange membranes. Polymer (Guildf) 42, 359-373 (2001).

36 Atorngitjawat, P., Klein, R. J. \& Runt, J. Dynamics of sulfonated polystyrene copolymers using broadband dielectric spectroscopy. Macromolecules 39 , 1815-1820 (2006).

37 Chen, W. J. \& Martin, C. R. Gas-transport properties of sulfonated polystyrenes. J. Membr. Sci. 95, 51-61 (1994).

38 Hamad, F. \& Matsuura, T. Performance of gas separation membranes made from sulfonated brominated high molecular weight poly(2,4-dimethyl-1,6-phenylene oxide). J. Membr. Sci. 253, 183-189 (2005).

39 Fang, J., Guo, X., Harada, S., Watari, T., Tanaka, K., Kita, H. \& Okamoto, K. Novel sulfonated polyimides as polyelectrolytes for fuel cell application. 1 . Synthesis, proton conductivity, and water stability of polyimides from 4,4'-diaminodiphenyl ether-2,2' disulfonic acid. Macromolecules 35, 9022-9028 (2002).

40 Watari, T., Fang, J., Tanaka, K., Kita, H., Okamoto, K. \& Hirano, T. Synthesis, water stability and proton conductivity of novel sulfonated polyimides from 4,4'-bis(4-aminophenoxy)biphenyl-3,3'-disulfonic acid. J. Membr. Sci. 230, 111-120 (2004).

41 Tanaka, K., Islam, M. N., Kido, M., Kita, H. \& Okamoto, K. Gas permeation and separation properties of sulfonated polyimides membranes. Polymer (Guildf). 47, 4370-4377 (2006). 
42 Sakaguchi, T., Takeda, A. \& Hashimoto, T. Highly gas-permeable silanol-functionalized poly(diphenylacetylene)s: synthesis, characterization, and gas permeation properties. Macromolecules 44, 6810-6817 (2011).

43 Sakaguchi, T., Ito, H. \& Hashimoto, T. Highly $\mathrm{CO}_{2}$-permeable and -permselective poly(diphenylacetylene)s having imidazolium salts: synthesis, characterization, gas permeation properties, and effect of counter anion. Polymer (Guildf) 54, 6709-6715 (2013).

44 Sakaguchi, T., Kameoka, K. \& Hashimoto, T. Synthesis of sulfonated poly(diphenylacetylene)s with high $\mathrm{CO}_{2}$ permselectivity. J. Polym. Sci. Part A 47, 6463-6471 (2009).

45 Sakaguchi, T., Shinoda, Y. \& Hashimoto, T. A series of poly(diphenylacetylene)s bearing sulfonic acids: synthesis, characterization, and gas permeability. Polymer (Guildf) 53, 5268-5274 (2012).

46 Kouzai, H., Masuda, T. \& Higashimura, T. Synthesis and properties of poly(diphenylacetylenes) having aliphatic para-substituents. J. Polym. Sci. 32, 2523-2530 (1994).
47 Silverstein, R. M. \& Webster, F. X. in Spectrometric Identification of Organic Compounds. 6th edn. (Wiley, New York, NY, USA, 1997).

48 Teraguchi, M. \& Masuda, T. Synthesis and properties of polyacetylenes with adamantyl groups. J. Polym. Sci. 37, 4546-4553 (1999).

49 Tsuchihara, K., Masuda, T. \& Higashimura, T. Polymerization of diphenylacetylenes with bulky silyl groups and polymer properties. J. Polym. Sci. 31, 547-552 (1993).

50 Teraguchi, M. \& Masuda, T. Polymerization of diphenylacetylenes having very bulky silyl groups and polymer properties. J. Polym. Sci. 36, 2721-2725 (1998).

51 Aoki, T., Kobayashi, Y., Kaneko, T., Oikawa, E., Yamamura, Y., Fujita, Y., Teraguchi, M. Nomura, R. \& Masuda, T. Synthesis and properties of polymers from disubstituted acetylenes with chiral pinanyl groups. Macromolecules 32, 79-85 (1999).

52 Kouzai, H., Masuda, T. \& Higashimura, T. Polymerization and polymer properties of diarylacetylenes. Polymer (Guildf) 35, 4920-4923 (1994).

53 Robeson, L. M. The upper bound revisited. J. Membr. Sci. 320, 390-400 (2008).

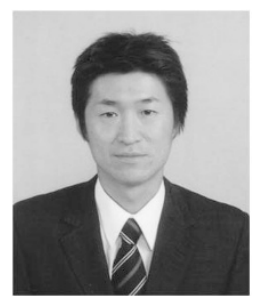

Dr Toshikazu Sakaguchi was born in Osaka, Japan in 1977. He received his Doctoral degree of Engineering in 2006 from Kyoto University under the supervision of Professor Toshio Masuda. He is currently an Associate Professor at the Department of Materials Science and Engineering, Graduate School of Engineering, University of Fukui. His research interests include transition metal-catalyzed polymerization, gas separation membranes, luminescence materials and synthesis of conjugated polymers including substituted polyacetylenes, poly(p-phenyleneethynylene)s and poly(p-phenylenevinylene)s. He was a recipient of Award for Encouragement of Research in Polymer Science, the Society of Polymer Science, Japan in 2011.

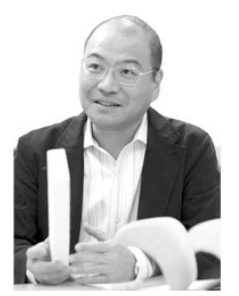

Dr Tamotsu Hashimoto was born in Kyoto, Japan in 1960. He received his B.S. degree in chemistry from Doshisha University in 1983 and his M.S. degree in chemistry from Kyoto Institute of Technology in 1985. He received his Ph.D degree in polymer chemistry from the Kyoto University in 1991 under the direction of Professor Toshinobu Higashimura and Professor Mitsuo Sawamoto. He started his academic carrier at the Shiga Prefectural Junior College in 1987 and moved to the University of Fukui as Associate Professor in 1991. He is currently Professor of Department of Materials Science and Engineering, Graduate School of Engineering, University of Fukui. His research interests include controlled polymerization and the development of degradable polymers for chemical recycling. 